\title{
Probe into the reform of College Chinese Teaching
}

\author{
Hongqin Chen \\ Literary College. Zhengzhou Normal University, Zhengzhou,450044, China \\ email: houying69@163.com
}

Keywords: College Chinese; Teaching reform; Quality education

\begin{abstract}
College Chinese is an important basic course for non-Chinese majors in Colleges and universities. It plays an important role in improving college students' humanistic literacy, language expression, writing, aesthetic ability and so on. However, in today's colleges and universities, the College Chinese has been marginalized: students do not want to learn and teachers do not know how to teach. To explore the reasons, it is imperative to reform the College Chinese.
\end{abstract}

\section{Introduction}

College Chinese course is main position or ways for undergraduate culture quality education. First, the purpose of College Chinese course is to improve students' Chinese proficiency and ability to use Chinese characters. Second, College Chinese course contains the essence of traditional culture, which influences the world with excellent traditional culture under the background of reform and opening-up. Third, College Chinese could promote the spiritual civilization. However, in today's university campus, the College Chinese course pays no attention. Undergraduates think it is unnecessary to learn it, and teachers do not know how to teach. In accordance with the above reasons, it is necessary to carry on the reform in the College Chinese course.

\section{The student's language ability is low}

In 1978, Kuang Yaming, President of Nanjing University, and Su Buqing, President of Fudan University, and other scholars and experts advocated the reestablishment of college Chinese courses in various colleges and universities throughout the country, in order to improve students' Chinese proficiency and their ability to use traditional culture. Today, do these experts have a good desire to achieve it? Let's look at these materials: in school education, compares to the strength of English, Chinese seems particularly lonely and becomes a "forgotten corner". A survey shows that $88 \%$ of the public believe that the Chinese level of college students decline and written expression ability of them degrade. Seoul, South Korea's "Central Daily" has published an article entitled "chilling Chinese knowledge of Chinese." The article refers to a translation qualification examination held in Shanghai. The English proficiency of the people who take part in the test is very high, but some people's Chinese level is unfortunate. In the Chinese-English title, some people actually translated "wealth cannot be obscene" into "rich but not sexy". According to the Xinhua News Agency, a translation competition jointly organized by the Shanghai Translators Association and Shanghai Translation Publishing House broke out: due to the lack of the best translation, the contest not only the first prize is vacancy, but also the second prize is awarded to a Native of Singaporean Yao Dengnan. As can be seen from the above material, College Chinese not only failed to play a positive role, which strengthen the ability of Chinese, broaden their horizons and enhance the quality of humanities, etc. But embarrassed by the reality: students do not want to learn the College Chinese and some teachers who do not want to teach College Chinese are in order to make up the class before the choice of College Chinese course. So what is the reason for this phenomenon?

\section{The reasons why students are not willing to study College Chinese}

In the first place, students are disappointed with the content and methods of teaching teachers.

The university students who have experienced the baptism of the university entrance exam into the hall have an initial desire of College Chinese course: the students can expect to hear the voice of 
the master. Through teachers' specific teaching to the classical literary works, the students feel the mood and image may edify emotional experience, the resonance of the mind and spirit and appreciate the essence of the splendid culture of the motherland. However, several classes later, they are disappointed. Because university teachers are not different from the secondary school teachers, university teachers still teach classical Chinese in the translation of words and phrases and still teach modern Chinese in the analysis of background and authors, key sentences and paragraphs.

So the College Chinese has become 'the senior Chinese'. The college students fall asleep, play games and read extracurricular books. College Chinese teachers do not pay attention to what the students want, only according to their own teaching plan for teaching. But students are not interested in these repeated courses which College Chinese textbooks on same items in secondary school students have studied. Some teachers do not interact with the students at all, and once they finish class, they do not listen to the students' views on the course. All these have deepened students' disappointment in the course of College Chinese.

In the next place, In today's impetuous utilitarian society, everyone is only looking at immediate interests, regardless of the long-term. As a member of society, college students are inevitably affected by this idea which is from a practical point of view. Every day they are busy in grading English PTES, take a professional certificate and prepare for future employment.

In contrast, they feel the College Chinese seems to be purely redundant because the course is the level off and do not take the certificate. Even if College Chinese is listed as a public compulsory course, the students' ultimate goal of learning is to get more than pass. If the students get the credits, they will be satisfied. The teachers are speaking of the hit off at the podium in the classroom, but students do not listen to the teachers, what they are interested in other things. Faced with such classes, such students, the teaching enthusiasm of teachers has been hit.

\section{The reason why teachers do not want to go to College Chinese}

First of all, College Chinese belongs to a general education course, and has nothing to do with the professional, so anyone who is not enough to teach class teaching hours can teach College Chinese. Due to the influence of the University specialized education, the position of the College's Chinese course has lost its glory, which has been pushed to the edge from the center back. [1]Since it is to cope with the class hours, teachers will not spend too much time in the course, most of them are muddle along, step by step, not for innovation. As long as the students do not advise, this course will remain unchanged on the go. The teachers always have finished classes and immediately leave, who do not listen to the expectations of students in the university language curriculum, do not ask students in the classroom whether they have harvest and no matter what kind of mental states students are in the class.

The other, the expectations of college students to College Chinese courses is relatively too high, so good College Chinese course is not easy. It requires teachers to have extensive knowledge and profound cultural accumulation, they can cite the content of the text, and they also need to have their own views on hot issues in society with a certain breadth and depth. "College Chinese" is the language of the university which is in a higher level of sense of language literacy and ability training that is, compared to the basic education of the Chinese language class. This requirement is very high, so Mr. Xu Zhongyu has repeatedly stressed: we open (College Chinese) this course and we must find the most extensive knowledge of the teacher to teach in the department." (SOCIAL SCIENCE newspaper, January 8, 2004 Fifth Edition) "College Chinese" is a comprehensive and difficult course, which requires a highly learned and experienced teacher who love teaching, and it is not easy for a person to achieve this kind of state. Therefore, a good College Chinese course is not easy, no one accidentally will become a "senior Chinese". The results leads to the students have tired of studying and the teacher has tired of teaching. 


\section{College Chinese strategies and methods of teaching reform}

\section{Change the spoon-feeding teaching methods of the past and give the classroom initiative to the students}

In the primary and secondary school teaching reform carried out in full swing today, the College Chinese classroom is still silent. At present, the teaching methods of College Chinese are still lagging behind. College Chinese teaching should take advantage of its practical characteristics and should be extended to extracurricular.[2] It is necessary to change the teacher "what I say goes" situation and bring out initiative of the students, we should introduce the discussion style and inquiry-based learning methods into the classroom. For example, in the text "Do what you love and love what you do", teachers could let students discuss today's frequent job-hopping phenomenon "as a college student, how do you look at work" as the theme. This class not only expands the content of teaching which let students consider the prevalence of job-hopping in today's society, but also introduce the discussion method in College Chinese teaching in order to improve the teaching methods and strengthen the interaction between teachers and students, at the same time it can mobilize students' interest in learning. To find the interests of students, we and students can explore specific situations, put forward the corresponding problems, encourage and guide students to self-learning. If it is necessary, the teachers can give guidance on learning methods. The "award to the fishing” approach can be a good way to enhance students awareness of the subject and improve their self-learning ability. As long as the teachers and students work together, the methods of teaching and learning throughout, we will be able to consolidate and develop the quality of students' autonomous learning, so that they can benefit from life.

We neglect the training of language ability, especially the lack of basic practical writing training. We will encounter many difficulties and troubles in completing the graduation thesis or graduation design, the job hunting and work in the future. Therefore, we must take into account the humanities and language education tools to comprehensively enhance the students' language literacy.

\section{The proper use of multimedia teaching}

Multimedia is the comprehensive display of text, pictures, sound and animation in one set, which makes full use of multimedia visual and auditory processing, using the combination of static and dynamic processing, stimulate innovative thinking, broaden their horizons, mobilize the enthusiasm of learning. The application of multimedia presentation, teaching content can be illustrated with a combination of static and dynamic, coupled with melodious music and appropriate sound effects; it can create a more creatable learning atmosphere. The author has done a survey of students and found that more than $96 \%$ of the students on the multimedia teaching hold a positive and welcoming attitude. At present, the multimedia teaching has been popularized, and the majority of teachers have begun to use the multimedia tools such as courseware in the process of teaching. Multimedia teaching and electronic lesson plans have its remarkable characteristics which combine a large amount of information, pictures and audio combination. The application of multimedia teaching not only can save time on the blackboard, but also mobilize the students' emotion, attention and interest from various angles. College Chinese teachers should constantly update and expand the knowledge, and regularly master new teaching skills and methods, which organically combine the traditional teaching methods with teacher's personal characteristics, multimedia assisted teaching. While dealing with the relationship between multimedia, blackboard, general teaching aids and language expression, in a word, the teachers should have an effect on improving the students' interest in learning.

\section{The teaching methods should be flexible and changeable}

Practice has proven that the interaction between teachers and students, flexible teaching methods, reasonable utilization of advanced media teaching and rich and colorful extracurricular activities can effectively stimulate students interest in learning, cultivate and improve the students' listening, speaking, reading and writing ability of comprehensive understanding and using the native language.[3]The diversification of teaching methods and teaching contents should be based on the following basic points: literature (culture), ideology and life. At the end of the class the teachers tell about the content with some social hot issues or concerns of the students to let students discuss, 
such as "food safety how do you see", "Diaoyu Islands", "the relationship of professional and employment" and "our dream at the university " and so on. These questions are of attention and interest to the students, who tend to speak and express positively about their opinions. On the one hand, the teaching method can exercise the students' ability of language skills, on the other hand, it let their brains relax appropriately, for the next attentively concentrate on lectures, and it actively creates the conditions to interact with students. The interpretation of the text should link to the current social life, the growing pains of students, and mental confusion and employment problems of college students. Only to find their interest, it can arouse students' interest in College Chinese, because as the proverb goes "interest is the best teacher".

According to the text the teachers can also add some knowledge to the students. Such as "having dinner" in this text, by the meal extension, the author talks about western etiquette, Chinese etiquette and some knowledge on the table. The students are very interested and have said that the knowledge to their future employment and human life is very helpful. The teachers should intersperse with more etiquette knowledge in the classroom teaching.

The teachers should boldly invite virtuosos to the College Chinese class, in order to let the students feel of great ingenuity. As in the teaching of Li Qingzhao "Slow, Slow Tune", the author briefly introduces the first word, and then has invited the dean of Beijing Normal University professor Kang Zhen to the classroom-playing the video about professor Kang in Lecture Room who has talked about the great poem. Professor Kang Zhen can make the students approach the great poet Li Qingzhao and appreciate the poetic charm of Li Qingzhao. Professor Kang Zhen has vivid explained the poem with beautiful pictures and melodious music, so every student has absorbed in the lecture and deeply appreciated the charm of Li Qingzhao.

Enhance the curriculum status, strengthen the construction of teaching staff and curriculum research

In primary and secondary schools, the Chinese language is one of the core subjects, because it involves the college entrance examination, which related to the future and destiny of students. Therefore educational management department, teachers, students and their parents at all levels attach great importance to the subject. While in the university stage, although the Chinese language has been also identified as the public basic courses in most universities, its status has been marginalized due to the impact of the professionalization of the university education. From the situation of College Chinese course setting, some school leaders attach importance to it and have already been included in the normal track. Some schools leaders do not pay attention to it or reduce the class hours, even do not open or close the subject, so there are some randomness and instability. From the class periods, the total class hours of Chinese language in most colleges and universities is only 36 or 54 hours. From the teachers' allocation, the College Chinese courses teachers are parttime teachers, or young teachers, or the weak research ability of teachers, in short, teachers' allocation is relatively weak. Some schools calculate the class periods on discount, which combat the enthusiasm of teachers and affect the quality of teaching.

The university administrative department of education should pay more attention to the teaching of the College Chinese when it is clear to determine the nature of College Chinese [4]. Specifically, we must first attach importance to the construction of teachers. All schools should establish a relatively stable, reasonable structure, a strong force of College Chinese teachers. The calculation of college Chinese class hours should not be discounted, which should be treated the same as the professional courses to improve the enthusiasm of teachers. Secondly, we should pay attention to the research and reform of College Chinese teaching. The teaching research of College Chinese is still stuck in the fragmented situation of individual research, and the research on group cooperation is very few. College Chinese is open to all non-Chinese major, because each profession has its own training objectives, so the teaching content and key points should also be different. Teachers should strengthen cooperation and work together to study, carry on the comprehensive research of multi angle and multi direction. On the basis of the research on the pilot reform, the successful experience gradually popularizes to the whole school, and even other institutions. Of course, the reform should be supported by the education authorities, in particular, the corresponding financial support. Third, 
we should increase the credits and the appropriate class hours of College Chinese, in order to improve the degree of attention to students to better achieve the teaching objectives.

\section{College Chinese teachers should improve their professional qualities.}

College Chinese as a basic course, the content of the course involves a wide range, both ancient and modern literature. In addition, the course contains the Chinese and foreign famous classics, with the need to talk about the ancient Chinese language [5]. It requires that college Chinese teachers should have a wide range of knowledge. Only in this way, the teachers can comprehend by analogy and teach vividly, more importantly, in order to stimulate students' interest in learning.

College Chinese teachers should establish the concept of lifelong learning, and fully realize the importance of lifelong education for teachers' professional development. Continuing education is a basic way to promote the professional development of College Chinese teachers. Continuing education can help Chinese teachers to renew educational ideas, improve their teaching methods, and improve their ability of scientific research. College Chinese is the main way of continuing education. It includes: first, the combination of off campus learning and school learning, which makes full use of the off-campus and on campus resources. Second, the long-term academic training and short-term communication should combine. Third, the key training and general improvement should combine.

College Chinese teachers should constantly adjust their existing knowledge structure, and regularly absorb the new scientific and cultural knowledge in order that College Chinese teachers can update and optimize the knowledge structure. In addition, College Chinese teachers should train and improve their basic academic research literacy, including the cultivation of strong consistent curiosity and enthusiasm for knowledge and scientific research, which is the source of scientific research. Only in this way can we write a higher academic value of professional papers, monographs and so on.

Reflective teaching is an important way to promote the professional development of College Chinese teachers. First of all, the reflective teaching has to guide teachers to active learning and the new extension, which is conductive to the sustainable development of the professional ability of College Chinese teachers. Secondly, reflective teaching can promote teachers think of the teaching process, which helps College Chinese teachers sublimate their own experience into teaching theory. Thirdly, reflective teaching can promote teachers to explore the teaching problems, which will help College Chinese teachers improve the rationality of teaching practice. In the end, the reflective teaching can strengthen the sense of professional ethics of teachers, and achieve the function of humanistic quality education in College Chinese course.

\section{Reform of curriculum assessment methods}

If College Chinese teaching reform receives a good effect, the curriculum assessment should be the corresponding reform. Evaluation system plays the role in the teaching activities of the status of the teaching process as the wind vane, and it directly impacts on the direction of teaching activities and teaching objectives how they can be achieved [6]. Indeed, students are often very concerned about the way of the curriculum assessment in the class. If a course is easy to pass at the end of the term, students will lose enthusiasm for this course, so they will not put too much time and make effort in this course. Only by taking a scientific and reasonable assessment method, can we better mobilize the initiative of students' learning. The improvement of humanistic quality depends on the usual reading and accumulation, so the College Chinese course should emphasize on the regular grade. For example, according to the class rate, homework, speech in the class, speech contests, reading essays and so on, these factors determine the regular grades of students. In the author's college, the total mark of the College Chinese course is divided into two parts: the regular grade and the final exam grade, which account for $60 \%$ and $40 \%$. This practice has increased the proportion of regular grades in order to fully mobilize the autonomy and enthusiasm of students to learn the College Chinese. In my opinion, if the students well do homework, they will achieve a good result 
in the final exam. The final exam as for as do not test or examine the rote content, but should be more open questions, so that students have something to say.

The reform of the College Chinese curriculum is not only related to the improvement of College Students' language proficiency, but also related to the overall improvement of college students' humanistic quality. The teaching reform of College Chinese course is still a long way to go, however, no matter how it changes, the humane function of the College Chinese, which improves the students' aesthetic pleasure ability and the cultural heritage, will not change. It is expected that the College Chinese course will take on such an important responsibility as soon as possible.

\section{Conclusion}

College Chinese plays an important role in improving college students' humanistic literacy, language expression, writing, aesthetic ability and so on. However, in today's colleges and universities, the College Chinese has been marginalized: students do not want to learn and teachers do not know how to teach. To explore the reasons, it is imperative to reform the College Chinese.

\section{References}

[1] Shuxiong Peng. College Chinese New Thinking [J]. Search, 2004 (5) 186.

[2] Gongwen Li. The Current Situation and Reform of College Chinese Education [J]. Literature Education, 2010, (02) 109.

[3] Kundao Yang. On The Current College Chinese Teaching Problems And Solutions [D]. Huazhong Normal University master's thesis, 2005:14.

[4] Dan Yi. The thinking and practice of the College Chinese teaching and learning reform[J]. Journal of North China Institute of Spaceflight Engineering, 2002, (1):5.

[5] Yi Wei. New version of College Chinese [M]. Beijing: Higher Education Press, 2007:8.

[6] Qingdong Kong. College Chinese teaching reform direction [J]. Chinese college teaching, 2006, (08):20. 